\title{
Complicated Crown-Root Fracture Treated Using Reattachment Procedure: A Single Visit Technique
}

\author{
Akhil Rajput, ${ }^{1}$ Sangeeta Talwar, ${ }^{1}$ Ida Ataide, ${ }^{2}$ Mahesh Verma, ${ }^{3}$ and Neeraj Wadhawan ${ }^{4}$ \\ ${ }^{1}$ Department of Conservative Dentistry and Endodontics, Maulana Azad Institute of Dental Sciences, New Delhi 110002, India \\ ${ }^{2}$ Department of Conservative Dentistry and Endodontics, Goa Dental College and Hospital, Bambolim, Goa 403202, India \\ ${ }^{3}$ Maulana Azad Institute of Dental Sciences, New Delhi 110002, India \\ ${ }^{4}$ Department of Orthodontics, All India Institute of Medical Sciences and Research Centre, New Delhi 110054, India
}

Correspondence should be addressed to Akhil Rajput, akhilraj_24@yahoo.com

Received 17 May 2011; Accepted 21 June 2011

Academic Editors: C. A. Evans and J. J. Segura-Egea

Copyright ( $\odot 2011$ Akhil Rajput et al. This is an open access article distributed under the Creative Commons Attribution License, which permits unrestricted use, distribution, and reproduction in any medium, provided the original work is properly cited.

Complicated crown-root fracture of maxillary central and lateral incisors is common in case of severe trauma or sports-related injury. It happens because of their anterior positioning in oral cavity and protrusive eruptive pattern. On their first dental visit, these patients are in pain and need emergency care. Because of impaired function, esthetics, and phonetics, such patients are quite apprehensive during their emergency visit. Successful pain management with immediate restoration of function, esthetics and phonetics should be the prime objective while handling such cases. This paper describes immediate treatment of oblique crown root fracture of maxillary right lateral incisor with reattachment procedure using light transmitting fiber post. After two and half years, the reattached fragment still has satisfying esthetics and excellent function.

\section{Introduction}

The increased incidence of traumatic injuries to anterior teeth is a consequence of leisure activities, where the most common injuries are crown fractures. These manifestations can vary from simple enamel-dentin fracture to complicated crown-root fracture or root fracture [1]. It has been estimated that about one quarter of the population under the age of 18 sustains traumatic injury in the form of anterior tooth fracture [2]. Out of this, $80 \%$ are central incisors and $16 \%$ are lateral incisors [3]. This is because of their anterior position and protrusion caused by the eruptive process [4]. Uncomplicated enamel and dentin fracture is most common while those involving crown and root with pulpal exposure constitute only $5-8 \%$ of all traumatic injuries [5-8]. A review of published case reports indicate that $85 \%$ of traumatized incisors fracture in an oblique fashion from labial to lingual aspect and the fracture line proceeds in apical direction [2]. The type and location of fracture depend upon age of patient, amount of force, and direction of blow [9].

Various methods and techniques were advocated to restore fractured teeth. In the late 60 's, temporary and permanent restoration of traumatized teeth in young individuals represented a severe challenge. Methods like resin crowns, stainless steel crowns with or without window preparation, pin-retained inlays, and complex ceramic restorations were in use [10]. All these techniques jeopardized tooth structure and were esthetically unacceptable. Moreover these techniques cannot be used in case of an esthetic emergency [11]. During the 70's, adhesive composite restorations almost became a standard procedure in the treatment of crown fracture in children, adults, and sometimes in elder persons. Other treatment options included porcelain laminate veneers, porcelain fused to metal crowns, and all ceramic crowns.

Acid-etch technique and advances in dentinal adhesives combined to drive a growing minimally invasive treatment philosophy among dentists, as evidenced by a renowned interest in the tooth reattachment procedure [12]. This is possible when tooth fragment is retrieved and preserved after trauma.

The advantages of tooth fragment reattachment over conventional composite restoration are conservatism, favorable wear mechanism, color match of the remaining crown portion, preservation of incisal translucency, maintenance of original tooth contours, preservation of identical occlusal 


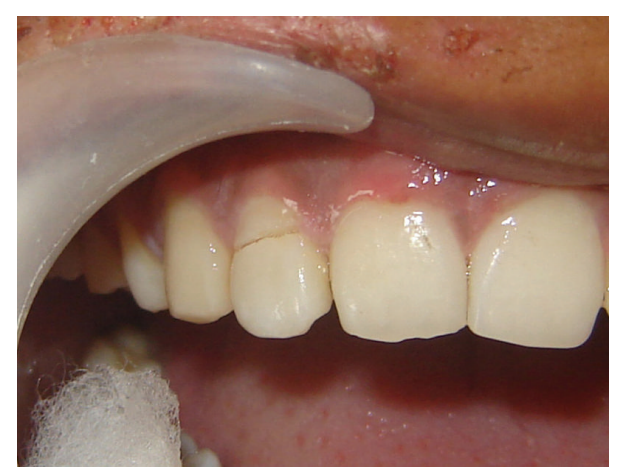

Figure 1: Preoperative view showing complicated crown-root fracture of maxillary right lateral incisor.

contacts, color stability of the enamel, cost effectiveness, and convenient single visit treatment [13-15]. The real merit of reattachment is the fact that it acts as a transitional restoration for a young patient who may need definitive prosthetic rehabilitations such as direct adhesive veneers or crowns in the event of reattachment failure [16].

Nowadays a number of successful reattachment cases and research are reported in literature [12, 16-22]. Still, the prevalence of reattachment procedures is low especially among general dental practitioners. It can be due to either lack of knowledge of such procedures or fear of failure.

\section{Case Report}

A 23-year-old patient reported to the dental hospital after 5 days of trauma and sustained a complicated crown-root fracture to the maxillary right lateral incisor (Figure 1). The fracture line was oblique extending in apical direction from labial to palatal surface. The margin on palatal surface was located about $1.5 \mathrm{~mm}$ from the free gingival margin and can be probed easily with a periodontal probe. The fractured fragment was attached to the root but was very mobile. Patient was very apprehensive about his fractured tooth. He was assured, and the condition was explained to the patient. Of the various treatment options explained to the patient, he preferred to retain the fractured fragments.

Since the fractured fragment of the maxillary left central incisor was attached to the underlying root at just one point so it was removed and stored in distilled water to be used at a later stage (Figures 2 and 3). Isolation was achieved using cheek retractor, cotton rolls, and saliva ejector placed in position. Gelatin sponge (Ab Gel, Sri Gopal Krishna Labs, Mumbai, India) was packed on palatal surface in the subgingival area to control any bleeding from that area (Figure 4). Single visit root canal treatment was completed, and the postspace was prepared. A light transmitting fiber post (D.T. Light post, Bisco, Schaumburg, USA) was tried in the canal and cut at the desired length. The fractured fragment was removed from the distilled water and tried on the cut end of fiber post. A groove was made on the fractured fragment so that it fits comfortably on the fractured root without any interference from overlying post

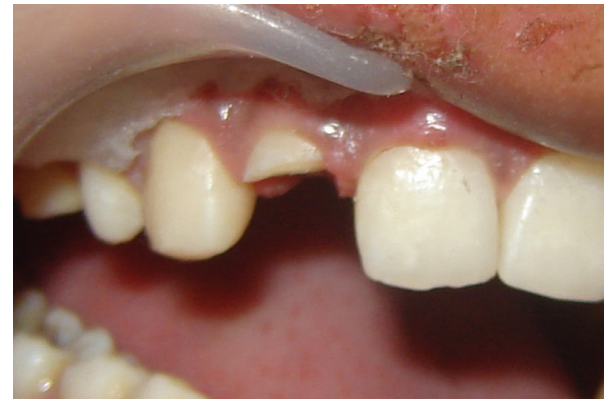

FIGURE 2: Fracture fragment removed from underlying tooth structure.

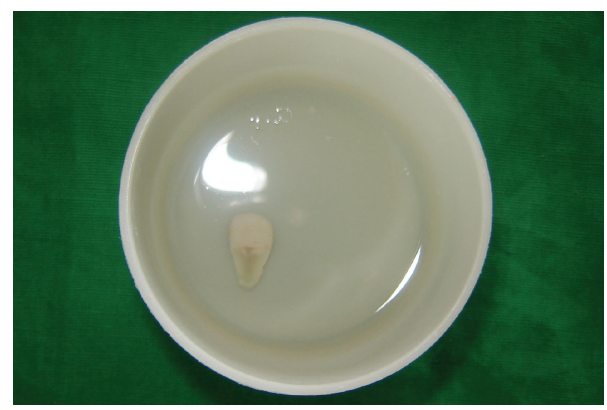

FIGURE 3: Fractured fragment stored in distilled water till further use.

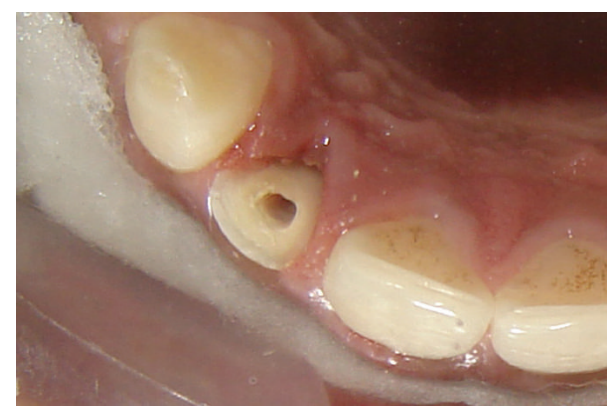

FIGURE 4: Gelatin sponge was packed on palatal surface in the subgingival area to control any bleeding from that area (mirror image).

(Figure 5). Remnants of pulp tissue from the fractured fragment were removed during this step. Care was taken not to remove excess dentin as it can alter the final esthetic appearance of the tooth. Once the desired fit was confirmed, it was again stored in distilled water. After acid etching with $37 \%$ phosphoric acid (Total etch, Ivoclar Vivadent AG, Bendererstrasse, Liechtenstein) of root canal, dual cure bonding agent (Prime and Bond NT dual cure, DENTSPLY Caulk, Milford DE) was applied as per the manufacturer's instructions, and the post was cemented with the help of dual cure resin cement (Calibra esthetic resin cement, DENTSPLY Caulk, Milford DE). Any excess cement oozing out of canal was removed with cotton applicator tips as it can alter the fit 


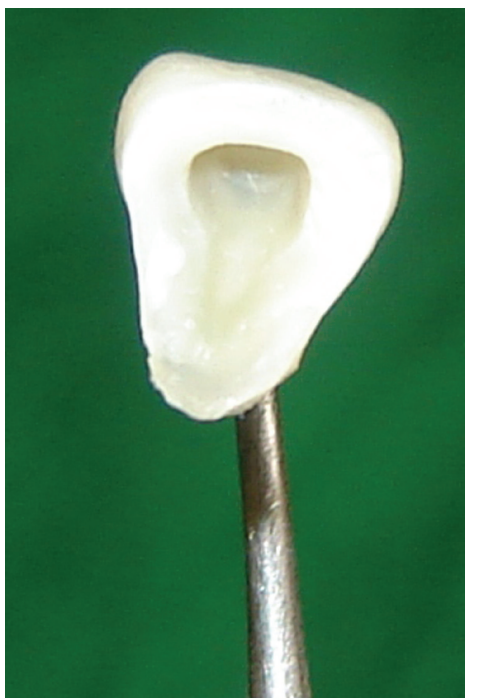

FIGURE 5: Groove prepared in the fractured fragment.

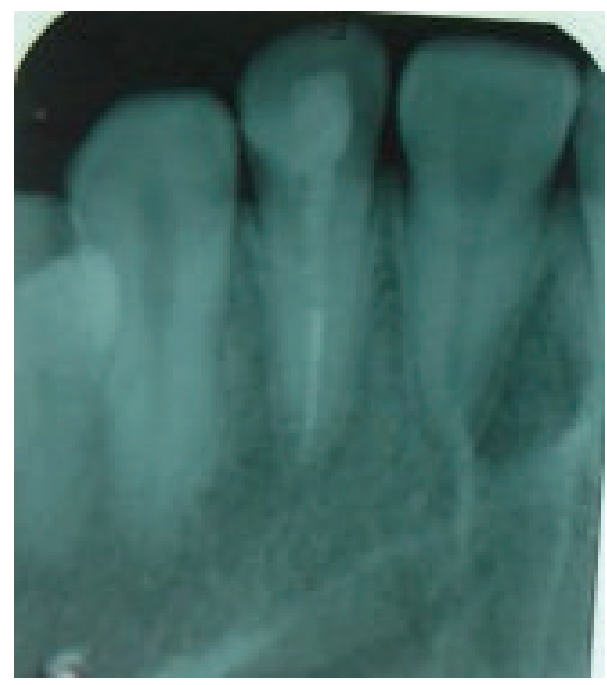

FIGURE 6: Single visit root canal treatment done and fragment reattached using fiber post and dual cure resin cement.

of the fragment. It was then light cured (QHL75 Curing Light, DENTSPLY, Addlestone, Surrey) for $40 \mathrm{sec}$. Gelatin sponge was then removed, and exposed root surface and fractured fragment were acid etched simultaneously. Groove in the fractured fragment was filled with dual cure resin cement, and the exposed fiber post was also luted with the same. The fragment was repositioned and cured for $40 \mathrm{sec}$. from palatal, labial, and incisal surfaces (Figure 6). Since the fracture line was visible on the labial surface, a groove was made app. $0.3 \mathrm{~mm}$ deep, extending app. $1.5 \mathrm{~mm}$ incisally and gingivally from the fracture line. It was then restored with Nanocomposite (Filtek Z350 Universal Restorative, 3M ESPE, St. Paul, Minn, USA) (Figures ?? and 8). Finishing and polishing was done using Sof-Lex polishing system (Sof-Lex

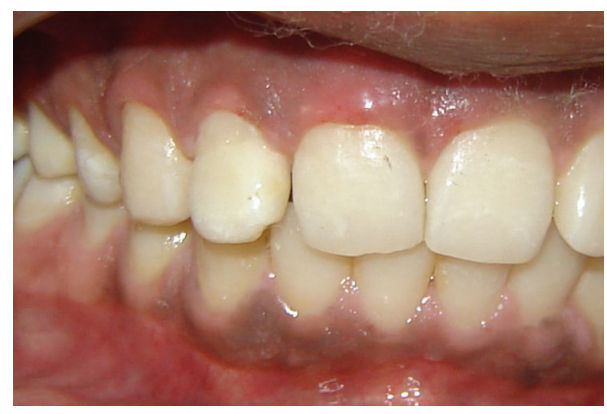

FiguRE 7: Labial view immediately after restoration of maxillary right lateral incisor.

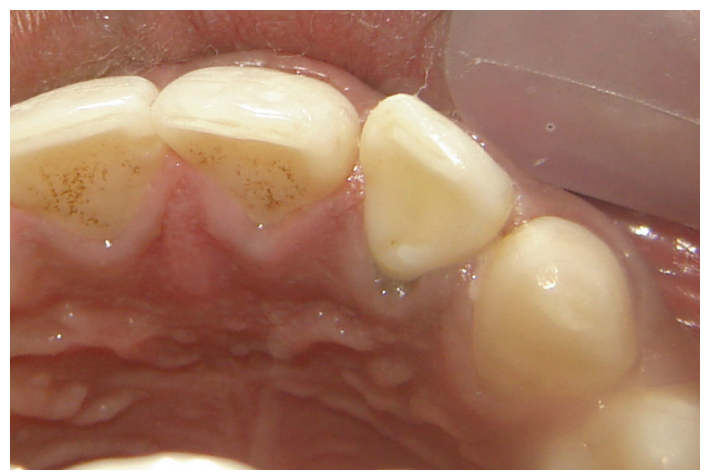

Figure 8: Palatal view immediately after restoration of maxillary right lateral incisor (mirror image).

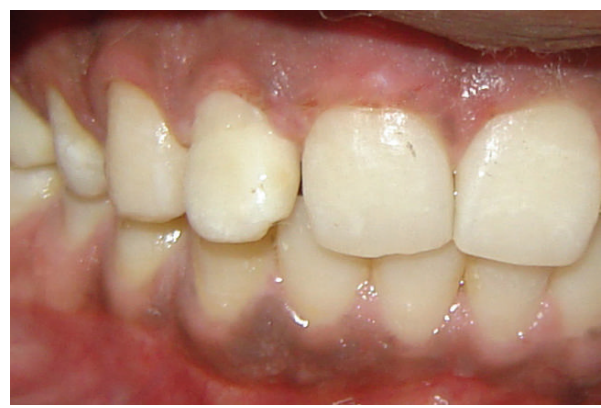

FIGURE 9: Labial view after two and half years.

Extra Thin Contouring and Polishing Discs, 3M ESPE, St. Paul, Minn, USA). Orthodontic extrusion of same tooth was planned after two week so as to bring the palatal fracture line supragingival and seal any defect, if present. But, the patient was so satisfied with the results after two weeks that he refused any further treatment.

After two and half years, the treated tooth has satisfying excellent esthetics and function (Figures 9 and 10). There was no mobility of any of the fragments, and the periodontal status in relation to maxillary right lateral incisor was satisfactory (no periodontal pockets with normally contoured palatal gingiva). Radiographic examination reveals satisfactory healing, and no discoloration was evident on clinical examination (Figure 11). 


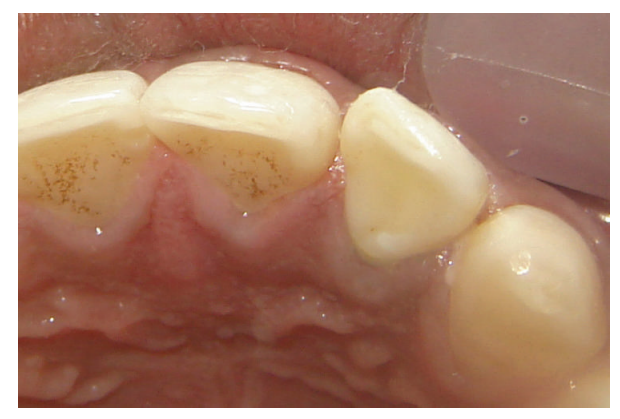

Figure 10: Palatal view after two and half years (mirror image).

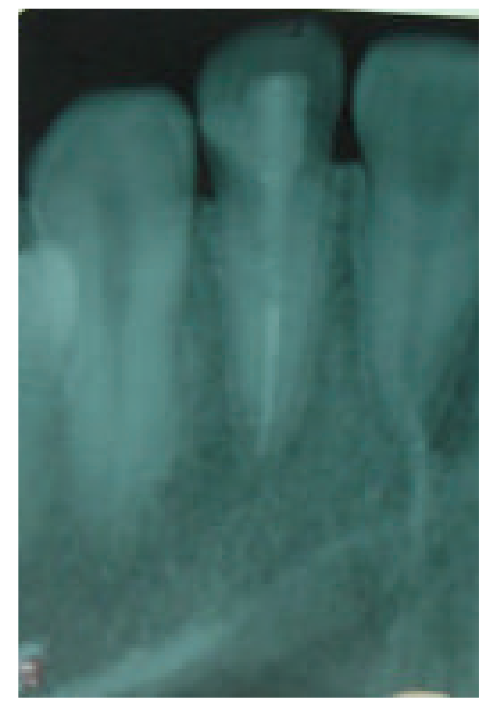

FIGURE 11: Radiographic appearance after two and half years.

\section{Discussion}

A patient with fractured anterior teeth usually reports with pain and is emotionally upset about his or her appearance [23]. Quick restoration of the esthetic appearance and relief of discomfort for these patients within a single appointment by preserving the natural tooth structure may lead to a positive emotional and social response from the patient. The technique described in this paper is simple, quick and economic as compared to other more invasive procedures. A number of case reports explain the successful reattachment of an uncomplicated tooth fracture cases. This paper signifies that the fragment can be used even if the fracture is complicated but if the margins are accessible. Isolation is the key to success in such cases. Rubber dam was not possible in this case, but adequate isolation was achieved using cotton rolls, cheek retractor, and gelfoam. Orthodontic extrusion, if required, can be planned once the other injuries of face have healed. It is to expose the fracture line to oral cavity and seal any visible defect at the margin. As with all traumatic injuries, followup is of critical importance. The patient should be followed for 3, 6, 12 months and yearly for 5 years [24]. Esthetics, tooth mobility, and periodontal status should be confirmed both clinically and radiographically at these follow-up visits.

\section{Acknowledgments}

The authors wish to thank Dr. Marina Fernandes, Dr. Rajan Lambor, Dr. Malika Tar, and Dr. Sumit Singla from Goa Dental College \& Hospital for their sincere help during treatment and formatting the paper.

\section{References}

[1] G. Holan and Y. Shmueli, "Knowledge of physicians in hospital emergency rooms in Israel on their role in cases of avulsion of permanent incisors," International Journal of Paediatric Dentistry, vol. 13, no. 1, pp. 13-19, 2003.

[2] D. F. Murchison, F. J. T. Burke, and R. B. Worthington, "Incisal edge reattachment: indications for use and clinical technique," British Dental Journal, vol. 186, no. 12, pp. 614-619, 1999.

[3] J. O. Andreasen and J. J. Ravn, "Epidemiology of traumatic dental injuries to primary and permanent teeth in a Danish population sample," International Journal of Oral Surgery, vol. 1, no. 5, pp. 235-239, 1972.

[4] J. O. Andreasen and F. M. Andreasen, Textbook and Color Atlas of Traumatic Injuries to the Teeth, Munksgaard, Copenhagen, Denmark, 3rd edition, 1994.

[5] E. B. Wood and T. J. Freer, "A survey of dental and oral trauma in south-east Queensland during 1998," Australian Dental Journal, vol. 47, no. 2, pp. 142-146, 2002.

[6] V. P. Liew and C. G. Daly, "Anterior dental trauma treated after-hours in Newcastle, Australia," Community dentistry and oral epidemiology, vol. 14, no. 6, pp. 362-366, 1986.

[7] I. G. Martin, C. G. Daly, and V. P. Liew, "After-hours treatment of anterior dental trauma in Newcastle and western Sydney: a four-year study," Australian dental journal, vol. 35, no. 1, pp. 27-31, 1990.

[8] J. O. Andreasen, Traumatic Injures of the Teeth, Saunders, Philadelphia, Pa, USA, 1981.

[9] J. O. Andreasen, "Etiology and pathogenesis of traumatic dental injuries. A clinical study of 1,298 cases," Scandinavian Journal of Dental Research, vol. 78, no. 4, pp. 329-342, 1970.

[10] M. G. Buonocore and J. Davila, "Restoration of fractured anterior teeth with ultraviolet-light-polymerized bonding materials: a new technique," The Journal of the American Dental Association, vol. 86, no. 6, pp. 1349-1354, 1973.

[11] J. O. Andreasen, "Buonocore memorial lecture. Adhesive dentistry applied to the treatment of traumatic dental injuries," Operative Dentistry, vol. 26, no. 4, pp. 328-335, 2001.

[12] N. Arhun and M. Ungor, "Re-attachment of a fractured tooth: a case report," Dental Traumatology, vol. 23, no. 5, pp. 322326, 2007.

[13] A. Reis, A. D. Loguercio, A. Kraul, and E. Matson, "Reattachment of fractured teeth: a review of literature regarding techniques and materials," Operative Dentistry, vol. 29, no. 2, pp. 226-233, 2004.

[14] L. N. Baratieri, A. V. Ritter, S. Monteiro Júnior, and J. C. de Mello Filho, "Tooth fragment reattachment: an alternative for restoration of fractured anterior teeth," Practical Periodontics and Aesthetic Dentistry, vol. 10, no. 1, pp. 115-127, 1998.

[15] A. Reis and A. D. Loguercio, "Tooth fragment reattachment: current treatment concepts," Practical Procedures \& Aesthetic Dentistry, vol. 16, no. 10, pp. 739-740, 2004.

[16] E. A. V. Maia, L. N. Baratieri, M. A. C. de Andrada, S. Monteiro, and E. M. de Araujo Jr., "Tooth fragment reattachment: fundamentals of the technique and two case reports," Quintessence International, vol. 34, no. 2, pp. 99-107, 2003. 
[17] M. D. Turgut, N. Gönül, and N. Altay, "Multiple complicated crown-root fracture of a permanent incisor," Dental Traumatology, vol. 20, no. 5, pp. 288-292, 2004.

[18] R. Nogueira Filho Gda, L. Machion, F. B. Teixeira, L. A. Pimenta, and E. A. Sallum, "Reattachment of an autogenous tooth fragment in a fracture with biologic width violation: a case report," Quintessence International, vol. 33, no. 3, pp. 181$184,2002$.

[19] E. Koparal and T. Ilgenli, "Reattachment of a subgingivally fractured central incisor tooth fragment: report of a case," Journal of Clinical Pediatric Dentistry, vol. 23, no. 2, pp. 113116, 1999.

[20] L. N. Baratieri, S. Monteiro Júnior, A. C. Cardoso, and J. C. de Melo Filho, "Coronal fracture with invasion of the biologic width: a case report," Quintessence International, vol. 24, no. 2, pp. 85-91, 1993.

[21] J. B. Ludlow and S. A. LaTurno, "Traumatic fracture-one-visit endodontic treatment and dentinal bonding reattachment of coronal fragment: report of case," The Journal of the American Dental Association, vol. 110, no. 3, pp. 341-343, 1985.

[22] I. A. Öz, M. C. Haytaç, and M. S. Toroğlu, "Multidisciplinary approach to the rehabilitation of a crown-root fracture with original fragment for immediate esthetics: a case report with 4-year follow-up," Dental Traumatology, vol. 22, no. 1, pp. 48 52, 2006.

[23] C. Mader, "Restoration of a fractured anterior tooth," The Journal of the American Dental Association, vol. 96, no. 1, pp. 113-115, 1978.

[24] A. Rajput, I. Ataide, and M. Fernandes, "Uncomplicated crown fracture, complicated crown-root fracture, and horizontal root fracture simultaneously treated in a patient during emergency visit: a case report," Oral Surgery, Oral Medicine, Oral Pathology, Oral Radiology and Endodontology, vol. 107, no. 2, pp. e48-e52, 2009. 


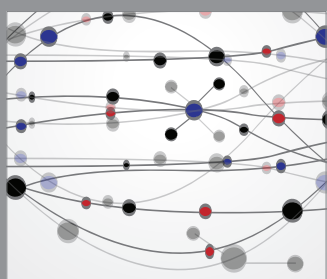

The Scientific World Journal
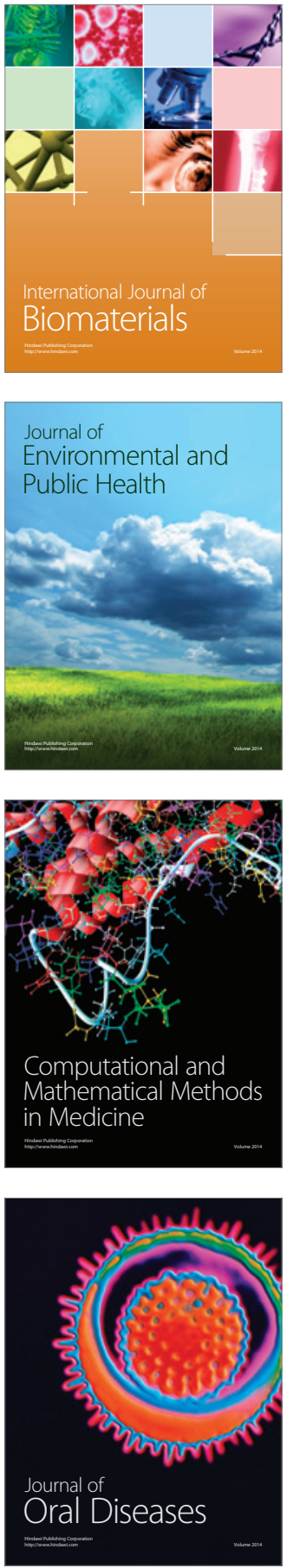
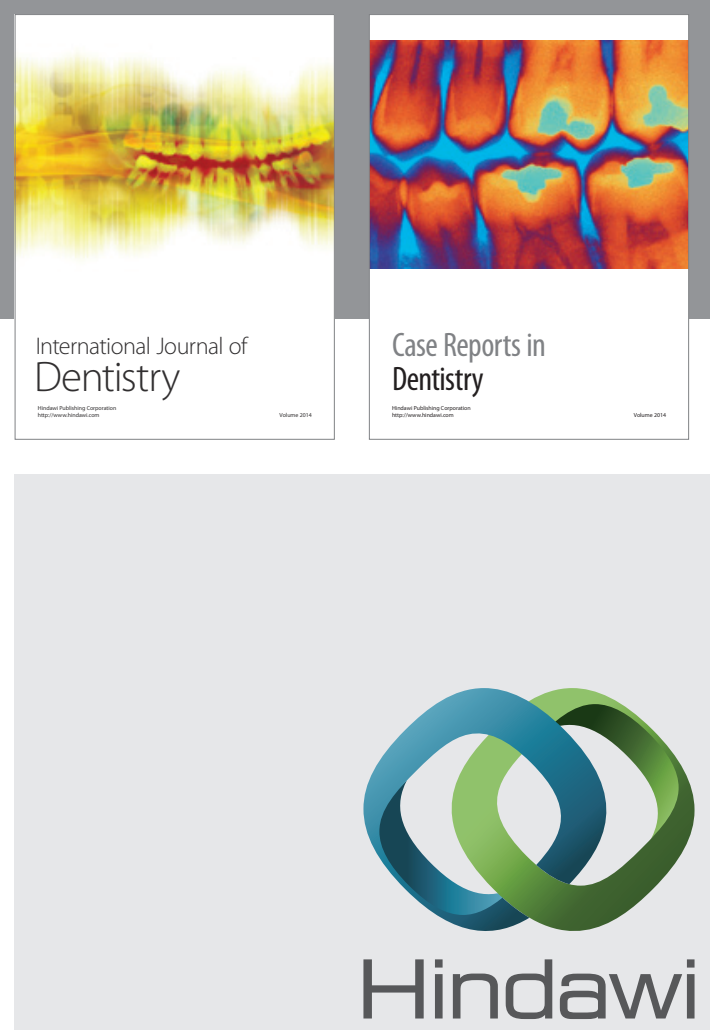

Submit your manuscripts at

http://www.hindawi.com
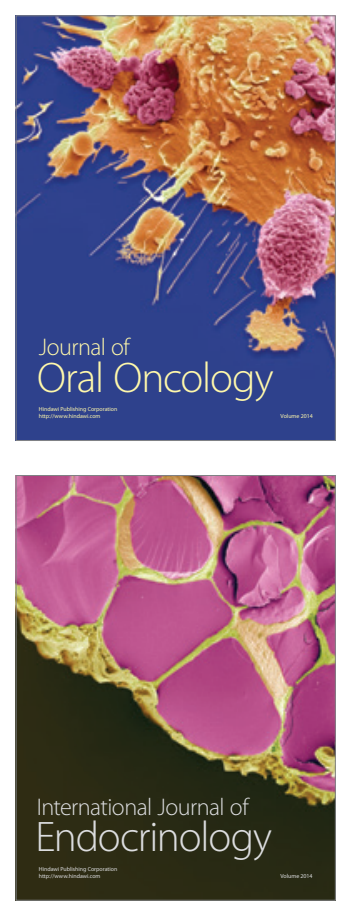
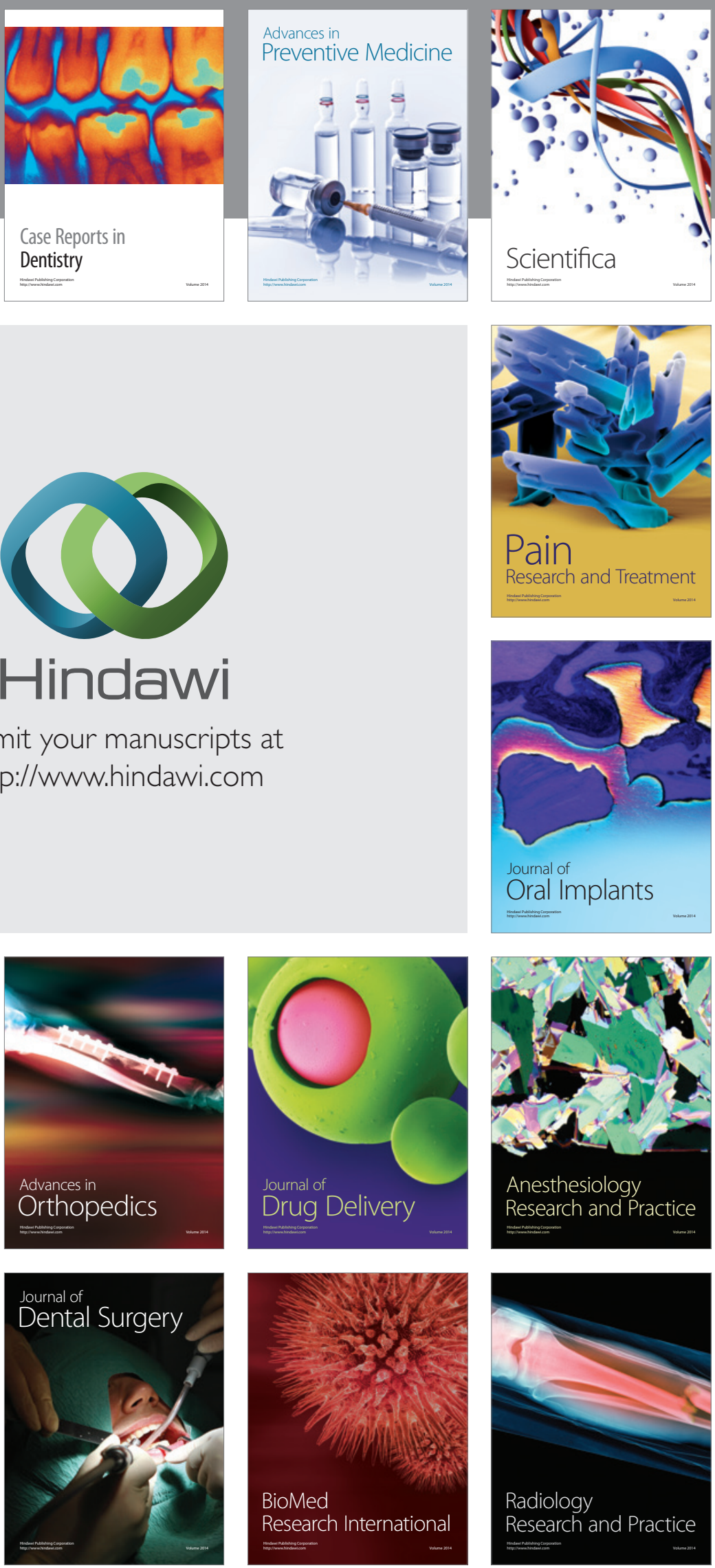